\title{
Management of Congenital Aortic Stenosis
}

\author{
JOHN M. REID, ERIC N. COLEMAN, and JOHN G. STEVENSON \\ From the University Department of Child Health; the Department of Cardiology, \\ the Royal Hospital for Sick Children; and the Cardio-Thoracic Unit, Mearnskirk Hospital, Glasgow
}

\begin{abstract}
Reid, John M., Coleman, Eric N., and Stevenson, John, G. (1970). Archives of Disease in Childhood, 45, 201. Management of congenital aortic stenosis. 72 patients with congenital aortic stenosis whose ages ranged from 1 month to 15 years were under supervision for periods ranging from several months to more than 9 years. The obstruction was subvalvar in 3. Additional malformations were aortic regurgitation, persistent ductus arteriosus, coarctation of the aorta, ventricular septal defect, partial anomalous pulmonary venous drainage, and mitral stenosis. Bacterial endocarditis complicated 3. Of 5 deaths unrelated to operation, 3 were sudden. Surgical treatment was carried out in 12 patients (commissurotomy, valve replacement with or without previous commissurotomy, subvalvar resection) with 2 deaths. 52 patients remained symptom-free. Detailed investigation to assess the patient for surgical treatment is indicated if symptoms are present or electrocardiographic evidence of severe left ventricular hypertrophy appears. Commissurotomy is, where possible, deferred until an age at which valve replacement can be undertaken if the stenosis cannot be adequately relieved without causing substantial regurgitation.
\end{abstract}

The introduction of cardio-pulmonary bypass surgery made relief of congenital aortic stenosis under direct vision possible (Ellis and Kirklin, 1962; Edwards and Jones, 1962), but uncertainty has persisted as to the clinical identification of critical obstruction and as to the optimum time for commissurotomy (Calatayud et al., 1964; Putnam et al., 1964; Morgan et al., 1965). Though adults are satisfactorily treated with the insertion of a Starr-Edwards prosthetic valve (Starr et al., 1963) or a valve homograft (Barratt-Boyes, 1964), children present technical difficulties in this respect, and the life-long anticoagulant therapy demanded by the prosthesis is an undoubted disadvantage. For these reasons, commissurotomy has remained the preferred operation for children with severe aortic stenosis. This communication based on a review of 72 consecutive patients reporting at a paediatric cardiac centre is concerned with indications for further investigation and surgery.

\section{Material}

Seventy-two patients whose ages at the time of this review ranged from 1 month to 15 years presented

Received 11 August 1969. between 1959 and 1968 . In all, the aortic stenosis was believed to be congenital because the murmur had been heard during the first four years of life and there was no history of acute rheumatism. There were 45 boys and 27 girls, and the period of follow-up extended from 1 to 9 years. 52 were undoubtedly symptom-free, while in 9 a history of tiredness related to exercise was difficult to evaluate; definite symptoms were exercise-provoked and consisted of dyspnoea with syncopal attacks (1), dyspnoea with praecordial tightness (2), and dyspnoea alone (8). All were subjected to clinical, radiographic, and electrocardiographic examination. The principal electrocardiographic sign taken as evidence of left ventricular hypertrophy was a sum of the RV6 and SV1 deflections greater than $30 \mathrm{~mm}$. in the first year of life, greater than $40 \mathrm{~mm}$. in the next 9 years, and greater than $45 \mathrm{~mm}$. thereafter. Depressions of the ST segment in the left chest leads, especially when accompanied by $T$ wave inversion, were considered to be of particularly serious significance in this respect.

Cardiac catheterization was performed in 21 patients, left ventricular angiography in 5 , and aortic root angiography in 8. These investigations were confined to patients with undue breathlessness on exercise or with symptoms suggesting myocardial or cerebral ischaemia, and to symptomless patients whose ECG revealed ST-T changes in the left chest leads, or steadily increasing left ventricular hypertrophy, or a substantial degree of left ventricular hypertrophy with neither ST-T changes nor steady deterioration. 


\section{Results}

Clinical features. The clinical signs of aortic stenosis had initially drawn attention to the diagnosis but they were not found to supply any assistance with the decision to be made on further investigation and surgical treatment. Signs of aortic regurgitation were present in one. On radiographic examination prominence of the ascending aorta was often the only abnormality. Prominence of the left ventricular apex was common, but over-all cardiac enlargement was unusual except in 2 cases where aortic stenosis was accompanied by aortic regurgitation. The ECG was regarded as being within normal limits in 40 , but in 32 there was evidence of left ventricular hypertrophy, with ST depression in V4-V6 in 5, and T wave inversion as an additional feature in a further 4 , these characteristics being interpreted as reflecting severe outlet obstruction.

The peak systolic pressure gradient over the left ventricular outlet in the 21 patients who underwent cardiac catheterization is indicated in Table $I$. Table II relates this to the degree of left ventricular hypertrophy as reflected by the ECG. The correlation coefficient ( $r$ ) between the sum of RV6 and SV1 and the systolic gradient over the left ventricular outlet was positive $(r=+0 \cdot 7025)$ and highly significant $(p>0.001)$.

TABLE I

Peak Systolic Gradient in 21 Patients

\begin{tabular}{c|c|c|c|c|c|c|c}
\hline $\begin{array}{c}\text { Systolic } \\
\text { Gradient } \\
\text { (mm.Hg) }\end{array}$ & $10-$ & $30-$ & $50-$ & $70-$ & $90-$ & $110-$ & $>129$ \\
\hline No. of patients & 5 & 4 & 4 & 2 & 1 & 3 & 2 \\
\hline
\end{tabular}

TABLE II

Systolic Pressure Gradient Related to Sum of RVG and SV1 (21 Patients)

\begin{tabular}{|c|c|c|c|}
\hline \multirow{2}{*}{$\begin{array}{l}\text { No. of } \\
\text { Patients }\end{array}$} & \multirow{2}{*}{$\underset{\text { Range }}{\mathrm{RV6}}+\underset{\mathrm{SV} 1}{(\mathrm{~mm} .)}$} & \multicolumn{2}{|c|}{$\begin{array}{l}\text { Systolic Pressure } \\
\text { Gradient (mm.Hg) }\end{array}$} \\
\hline & & Range & Mean Value \\
\hline $\begin{array}{r}6 \\
15\end{array}$ & $\begin{array}{c}0-49 \\
50-100\end{array}$ & $\begin{array}{l}10-40 \\
20-140\end{array}$ & $\begin{array}{l}20 \\
79\end{array}$ \\
\hline
\end{tabular}

Cine-angiocardiography from the left ventricle showed the level of obstruction in the outflow tract, and in 3 it was subvalvar. Supravalvar stenosis was not encountered. Aortic root angiocardiography in 2 patients confirmed that stenosis was accompanied by regurgitation.
Complications and early death. 6 patient $\frac{\rho}{2}$ (8\%) had an additional malformation. In 3 this. was a persistent ductus arteriosus, ligated withou $\overrightarrow{\overrightarrow{5}}$ incident. One had a ventricular septal defectoAn infant who died in congestive cardiac failure aE 1 month had preductal coarctation of the aorta asp. well as severe aortic stenosis. A boy of 11 years with subaortic stenosis, had mitral stenosis and partial anomalous pulmonary venous drainage irf addition. He had latterly developed exertiona $\vec{b}$ dyspnoea, and his ECG showed the pattern of left ventricular hypertrophy with ST depres sion in the left chest leads. He died suddenly two weeks after catheterization while playing draughts. Bacterial endocarditis occurred in 3 er 2 developed serious aortic regurgitation and 1 diedi 2 deaths occurred in boys aged 8 and 15 years during moderately strenuous exercise, football and swimming, respectively. Neither had had pre $=$ monitory symptoms. Both electrocardiograms indicated left ventricular hypertrophy but without ST depression in the left chest leads. One bot with mild aortic stenosis (peak systolic gradient. $20 \mathrm{~mm}$. $\mathrm{Hg}$ ) developed mitral valve disease after $\overrightarrow{0}$ acute rheumatism at the age of 9 years.

Surgical treatment. 12 patients had surgica treatment, the total number of operations being 14 홓 2 of 7 patients who underwent aortic commissuro@ tomy subsequently required valve replacemento because of a substantial degree of post-operative aortic regurgitation (Table III). One other age $\widehat{\Phi}$ 3 years died as a result of aortic regurgitation following commissurotomy on a severely stenose bicuspid valve.

TABLE III

Surgical Procedures in 12 Patients

\begin{tabular}{|c|c|c|}
\hline Procedure & No. & Deaths \\
\hline $\begin{array}{l}\text { Comissurotomy } \\
\text { Aortic valve replacement } \\
\text { Open excision of subvalvar obstruction }\end{array}$ & $\begin{array}{l}7 \\
6 \\
1\end{array}$ & $\begin{array}{l}1 \\
1 \\
0\end{array}$ \\
\hline
\end{tabular}

The ages of those who underwent commissurod tomy ranged from 3 to 15 years, and the survivort్టు have been under supervision for 1 to 7 years. Aortic valve replacement was confined to patienţ beyond the first decade of life, the youngest bein 11 years; in 1 patient there was pre-existing? regurgitation, in 2 the valve was bicuspid, and in the fourth, requiring valve replacement as the्छ primary operation, the small valve ring made successful commissurotomy impossible. 
Remaining patients. Of the survivors without operation, a further 2 patients who recently developed symptoms and increasing left ventricular hypertrophy were catheterized, and at the age of 9 and 12 years await aortic valve replacement. 52 patients remained well and symptom-free during the period of follow-up, and with no electrocardiographic sign of increasing left ventricular hypertrophy there has been no indication for further investigation or treatment. These patients appear to have relatively mild obstruction, but this might become more severe in the future were the valve to become calcified or distorted as a result of either infection or progressive sclerosis.

\section{Discussion}

This series showed the expected male preponderance $(5: 3)$ though not to the same extent as those of Nadas (1963) and of Putnam et al. (1964) in which males outnumbered females by $5: 1$ and $4: 1$, respectively.

It is essential first of all to identify patients with severe aortic stenosis because it is among these that sudden death is most likely and operative treatment must therefore be considered (Wood, 1960). Putnam et al. (1964) estimated that sudden death occurred in $5-10 \%$ of children with aortic stenosis and Campbell (1968a) that just over $25 \%$ of those alive at the age of 1 year die before the age of 20 years. During the period of this review 15 of our patients $(21 \%)$ gave clear evidence of clinical deterioration. Of the 5 non-surgical deaths $(7 \%$ of all patients) that of the 4-week-old infant who presented in congestive cardiac failure was attributable at least in part to preductal coarctation of the aorta. However, isolated aortic stenosis sufficiently severe to be complicated by congestive cardiac failure in infancy carries a notably bad prognosis (Nadas, 1963; Friedberg, 1966). In addition to one older child who died of bacterial endocarditis and one with a complicated malformation who died during sedentary activity, 2 died suddenly during moderate exertion. Neither of these had ST depression or $T$ wave inversion in the left chest leads of the electrocardiogram; the child who died suddenly while sitting had ST depression without $T$ wave inversion, and all 3 gave other electrocardiographic evidence of substantial left ventricular hypertrophy. Only one had experienced any symptoms. Campbell (1968b) found that $80 \%$ of deaths from aortic stenosis were sudden but that only $5 \%$ had a definite association with strenuous exercise. Even in the absence of symptoms, electrocardiographic evidence of left ventricular hypertrophy with any degree of ST-T depression over the left praecordium is now taken by us to indicate severe outlet obstruction and the urgent need to measure the systolic gradient over the left ventricular outlet. In the absence of ST-T changes, electrocardiographic evidence of left ventricular hypertrophy of more than a mild degree justifies the same investigation but with a lesser degree of urgency.

A very significant positive correlation existed between the magnitude of the systolic gradient and the sum of RV6 and SV1, but accurate predictions from the ECG as to the extent of the gradient in individual cases could not be made because of the wide scatter of some observed values. In the age period of those catheterized (9-15 years), if the sum of RV6 and SV1 exceeded $50 \mathrm{~mm}$. the systolic gradient was likely to exceed $50 \mathrm{~mm}$. $\mathrm{Hg}$. It is necessary, however, to record the disquieting observation by Nadas (1963) that severe aortic stenosis may be accompanied by a normal ECG. Hancock and Fleming (1960) in a study of 41 patients with aortic stenosis, but of whom only 6 were children, found a close correlation between the electrocardiographic evidence of left ventricular hypertrophy and the degree of obstruction. They found that $T$ wave inversion occurred in all those with symptoms and that the gradient over the aortic valve was greater than $60 \mathrm{~mm} . \mathrm{Hg}$ if the depth of the inverted $\mathrm{T}$ wave was more than $3 \mathrm{~mm}$. Unfortunately, this useful correlation was not substantiated in the present series in which it was found that a gradient of this order might be accompanied by an upright $T$ wave.

Other signs, such as the character of the arterial pulses or of the systolic murmur, or the radiographic appearances, were of little value in the assessment of the degree of obstruction. We cannot comment from our material on the positive correlation between delay in the maximum intensity of the murmur and the more severe grades of aortic stenosis, which has been pointed out by Oakley and Hallidie-Smith (1967).

Clinical evidence of aortic stenosis, productive of symptoms, or accompanied by electrocardiographic evidence of substantial left ventricular hypertrophy, requires that the site of the obstruction and the pressure gradient over the left ventricular outflow tract be determined. If severe valvar stenosis is found, the nature and the timing of surgical treatment must be considered. Cardiovascular symptoms which had constituted an indication for cardiac catheterization and angiography must also be an indication for surgical treatment, provided that the subsequent investigations have given reason for believing that the symptoms are a true reflection 
of organic disease. Similarly ST-T depression in the left chest leads has been regarded as an indication for both investigation and operation. Even in the absence of these features a systolic pressure gradient across the left ventricular outlet of at least $50 \mathrm{~mm}$. $\mathrm{Hg}$, with evidence of substantial left ventricular hypertrophy has been taken as an indication for surgical treatment. The timing of the operation is dependent not only upon the clinical urgency but also upon the suitability of the patient for valve replacement if commissurotomy should produce aortic regurgitation. This complication is particularly likely if the valve is bicuspid, and those affected can be expected to derive little benefit from surgical treatment which has replaced one anomaly by another at least as serious (Morgan et al., 1965). Apart from this immediate trouble commissurotomy may prove to be of no more than temporary benefit, and valve replacement may be required later because of progressive sclerosis, increasing regurgitation, or calcification of the aortic valve during adult life. Ellis and Kirklin (1962), reporting short-term results of commissurotomy on 47 patients (ages not given), did not detect significant aortic regurgitation in any of their 41 survivors, and this they attributed to meticulous conservation of cusps and commissures at operation. By contrast, 3 of the 6 survivors of our 7 patients who underwent an initial commissurotomy had a degree of post-operative regurgitation (significant in 2), attributable to the effect of operation and narrow valve ring with thickened distorted cusps. These 2 patients with significant postoperative regurgitation and 4 others (1 with preexisting regurgitation and 3 with an irreparable valve) were subjected to aortic valve replacement with a Starr-Edwards prosthesis.

When deciding on the timing of operative treatment, it has to be borne in mind that clinical deterioration may occur with increasing age, and that during the period of delay and deterioration sudden death may occur related or unrelated to strenuous exercise. This event is practically always preceded by electrocardiographic evidence of left ventricular hypertrophy, but not necessarily by features implying imminent disaster. Having weighed the hazards of operation against those of refraining from operation, we have adopted the policy of proceeding to commissurotomy or to subvalvar resection where detailed investigations, performed in accordance with the indications already discussed, have confirmed the existence of a substantial degree of stenosis and localized its site. If the valve is shown to be bicuspid a distinctly limited double commissurotomy may have to be accepted in order that severe post-operative regurgitation may be avoided. Whenever possible, we now make every effort to postpone operative intervention until the child is of an age (not less than 10 years) and of a size at which the valve ring is likely to accept a Starr-Edwards aortic prosthesis. In these circumstances, the surgical team can proceed to valve replacement if the commissurotomy leads either to inadequate relief of the obstruction or to an unacceptable degree of aortic regurgitation. Where detailed investigations reveal the coexistence of stenosis and regurgitation, the problem is regarded as one for medical management until an age is reached at which valve replacement becomes practicable. Patients accepted for operation and all whose preliminary investigations suggest the presence of more than mild aortic stenosis should be warned to avoid competitive sports and games. This seems the correct course to adopt, though we know that death may occur suddenly even when patients are at rest or engaged in quite gentle exercise. Not unexpectedly, however, the recommendation is not necessarily observed in practice; the 2 children who died during moderately strenuous exercise had been engaging in unsupervised activities. We are also particularly careful to underline the importance of penicillin cover for operations on the mouth, nose, or throat, including dental extraction, though such procedures seem seldom to be the causal event in cases of bacterial endocarditis during childhood.

We are indebted to our surgical colleagues, Mr. R. S. Barclay, Mr. T. M. Welsh, Mr. N. McSwan, and Mr. J. Bentley, who performed the surgical treatment on all the patients who required operation. We are grateful to Dr. J. A. Inall for his assistance and to the physicians who referred these patients to us.

\section{REFERENCES}

Barratt-Boyes, B. G. (1964). Homograft aortic valve replacement in aortic incompetence and stenosis. Thorax, 19, 131.

Calatayud, J. B., Schulz, K. J., Maranhao, V., and Goldberg, H. (1964). Acquired aortic stenosis in adults: findings of prognostic value in evaluation for surgical treatment. Fournal of $D$ Thoracic and Cardiovascular Surgery, 47, 337.

Campbell, M. (1968a). The natural history of congenital aortic stenosis. British Heart fournal, 30, 514.

- (1968b). Calcific aortic stenosis and congenital bicuspid aortic valves. British Heart fournal, 30, 606.

Edwards, F. R., and Jones, R. S. (1962). Congenital aortic stenosis. N Thorax, 17, 218,

Ellis, F. H., Jr., and Kirklin, J. W. (1962). Congenital valvular $\sigma$ aortic stenosis: anatomic findings and surgical technique. $<$ Fournal of Thoracic and Cardiovascular Surgery, 43, 199.

Friedberg, C. K. (1966). Diseases of the Heart. 3rd ed., p. 1128. Saunders, Philadelphia and London.

Hancock, E. W., and Fleming, P. R. (1960). Aortic stenosis. Quarterly fournal of Medicine, 29, 209.

Morgan, B. C., Guntheroth, W. G., Baum, D., and Merendino, $\bar{O}$ K. A. (1965). Reassessment of operative indication for moder- $(\mathbb{D}$ ate congenital aortic stenosis. Fournal of Thoracic and Cardiovascular Surgery, 49, 150. 
Nadas, A. S. (1963). Pediatric Cardiology, 2nd ed., p. 546. Saunders, Philadelphia and London.

Oakley, C. M., and Hallidie-Smith, K. A. (1967). Assessment of site and severity in congenital aortic stenosis. British Heart fournal, 29, 367.

Putnam, T. C., Harris, P. D., Bernhard, W. F., and Gross, R. E. (1964). The surgical management of congenital aortic stenosis. fournal of Thoracic and Cardiovascular Surgery, 48, 540.

Starr, A., Edwards, M. L., McCord, C. W., and Griswold, H. E.
(1963). Aortic replacement: clinical experience with a semirigid ball-valve prosthesis. Circulation, 27, 779.

Wood, P. (1960). Diseases of the Heart and Circulation. 2nd ed., pp. 347-349. Eyre and Spottiswoode, London.

Correspondence to Dr. J. M. Reid, Cardio-thoracic Unit, Mearnskirk Hospital, Newton Mearns, Glasgow. 